\title{
Impact of an educational intervention on knowledge and attitude regarding pharmacovigilance among health professionals working on cancer hospital attached to a regional pharmacovigilance center
}

Sunil Shrestha ( $\nabla$ sunilcresta@gmail.com )

Nepal Cancer Hospital and Research Center https://orcid.org/0000-0002-9174-7120

Sabina Sharma

Nepal Cancer Hospital and research Center

Ramesh Bhasima

Nepal Cancer Hospital and Research Center

Puskar Kunwor

nepal cancer hospital and research center

Baburam Adhikari

Nepal Cancer hospital and research center

Binaya Sapkota

Nobel College

Research article

Keywords: adverse drug reactions, drug safety, educational intervention, healthcare professionals, nurses, Nepal, pharmacists, pharmacovigilance

Posted Date: March 20th, 2020

DOI: https://doi.org/10.21203/rs.3.rs-18132/v1

License: (c) (1) This work is licensed under a Creative Commons Attribution 4.0 International License.

Read Full License

Version of Record: A version of this preprint was published at BMC Medical Education on June 3rd, 2020. See the published version at https://doi.org/10.1186/s12909-020-02084-7. 


\section{Abstract}

Aims: The main aim of the study was to assess the impact of a pharmacovigilance education intervention on the knowledge and attitude of healthcare professionals (HCPs) attached to a regional pharmacovigilance center in an oncology based hospital of Nepal.

Methods: Knowledge and attitude were studied before and immediately after the educational intervention among 89 HCPs working in a different department at an oncology based hospital of Nepal. A pretested questionnaire having twelve and nine statements for assessing knowledge and attitude were used. Responses were analyzed using descriptive and inferential statistics. The knowledge and attitude scores before and after educational intervention were analyzed with Wilcoxon rank-sum test, using SPSS version 21.0.

Results: The knowledge score was significantly increased from [mean \pm S.D (Ranges)] [6.90 \pm 2.527 (112)] to [11.36 \pm 1.189 (6-12)] after an intervention. The attitude score was also significantly increased from $[5.56 \pm 1.616(4-10)]$ to a $[6.97 \pm 1.793(4-12)]$ after an intervention. Twenty-one (23.6\%) of participants responded that they lacked the time to report adverse drug reactions (ADR), while $12(13.5 \%)$ of the participants replied that there was no remuneration for reporting ADR. Around $24 \%$ of them suggested for frequent pharmacovigilance awareness programs via Continuing Medical Education or workshop for improvement of pharmacovigilance.

Conclusion: The preliminary finds of this study showed that knowledge and attitude scores were increased following an educational intervention. It also suggests that training on pharmacovigilance and ADR tends to have a positive impact on knowledge and attitude among nurses and pharmacists working at an oncology based hospital of Nepal.

\section{Introduction}

Patient's wellbeing and safety while on medications is an important issue for all healthcare professionals (HCPs). As there is no mandatory regulation that Nepalese pharmaceutical manufacturers should report adverse drug reactions (ADRs) and correct data regarding adverse effects may not be available. An ADRs is "a response to a drug which is noxious and unintended, and which occurs at doses normally used in man for the prophylaxis, diagnosis, or therapy of disease, or for the modifications of physiological function" [1]. Pharmacovigilance (PV) is an organized procedure for observing and identifying ADRs [2]. It is the science and actions concerning the detection, assessment, understanding, and prevention of adverse effects or any other probable drug-related problems [3].

In the context of Nepal, the PV program was started in 2004 with the Department of Drug Administration (DDA) as a national PV center, which gathers case reports of ADRs from all regional PV centers in Nepal [4]. Out of 15 regional PV centers in Nepal, Nepal Cancer Hospital and Research Center (NCHRC), which is a comprehensive cancer care center of Nepal is a regional PV center that reports ADRs due to chemotherapeutic agents [5]. Cancer is a dreadful disease with a significant economic and health burden 
[6]. Antineoplastic drugs with high toxicity and narrow therapeutic window are used in oncology departments and the PV center is not available in every hospital. PV of antineoplastic agents is necessary for the safety of lives and to utilize available health resources cost-effectively [7]. In clinical practice, both from a clinical and economic point of view, ADRs may have a dramatic influence [8]. The economic burden on patients also decreases by reporting ADR reporting as an ADR causes additional treatment [9]. Underreporting confines and delays initiatives that could have been taken to avoid or lessen the harmful effects of medicines [10]. In addition, it is unethical not to notify or report harmful effects of a drug even subsequent to experiencing it, which may intentionally put the next user of the same medicines at risk [11]. Quick reporting of ADRs is reasonable and debatably, the greatest technique for drug safety surveillance [12]. ADR reporting and PV have significant public health implications as these contribute to the prevention of future similar types of ADR cases in the same and distant locations. This would save the precious lives and economies of the nations.

Globally, the effectiveness of the PV program is determined by the active involvement of HCPs. So as to improve a current PV program, there is a necessity to improve HCPs' knowledge attitude and practice (KAP). Before completing any intervention, it is important to assess the pattern of KAP of the HCPs with respect to $A D R$ monitoring and $P V$ so the intervention can be focused on, in light of the specific findings. The awareness, knowledge, and attitudes of the HCPs regarding PV and its existence in the country directly affect the practice of PV and ADR reporting in the hospital. Several studies have evaluated the importance of ADR reporting and knowledge, attitude and practice (KAP) of HCPs regarding the subject $[13,14]$. The awareness of HCPs regarding ADR reporting and PV in the country may ultimately improve ADR reporting [15] and it should be strengthened in every hospital [16]. Being key HCPs, doctors, nurses, and pharmacists have an immense responsibility in reporting ADRs and strengthening the existing PV mechanisms. PV training is given to increase the knowledge of PV among HCPs especially to nurses and pharmacists. Underreporting is a problem in Nepal and this study tries to address it. The knowledge, practice, and attitude of nurses and pharmacists working at NCHRC regarding PV are still unknown. This is the first study in a regional PV center attached to the oncology based hospital. There are several studies in Nepal which have reported that HCPs have a lack of knowledge regarding the PV before any kind of educational intervention [15, 17-20]. However, there are very few limited studies [21, 22] available after familiarizing the educational intervention about PV to HCPs of tertiary care hospital and community pharmacists [23]. With this background, the main objective of this present study was to assess the impact of educational intervention on the knowledge of PV and ADR reporting, attitude towards reporting ADR of HCPs (nurses and pharmacists) working in medical oncology departments and allied departments of NCHRC.

\section{Methods}

\section{Study Design}

The study was a cross-sectional study. 
NCHRC is an oncology hospital of Nepal with 100 beds which provides comprehensive cancer care, situated at Harisiddhi, Lalitpur, Nepal. This cancer hospital provides all types of treatment facilities to the cancer patients which includes chemotherapy, radiotherapy, and surgery. NCHRC is the first hospital in Nepal to start a regional PV center attached to a cancer hospital [5].

\section{Sampling Technique and Sample Size}

All 89 HCPs (nurses and pharmacists) who showed a willingness to participate in the training on "Pharmacovigilance and adverse drug reactions" working at the cancer hospital were enrolled in the study. The training was given by a team of regional PV center of this hospital. We have included only nurses and pharmacists in the study. The doctors, medical oncologists, and other HCPs were excluded from this study.

The sample size for the study was calculated using Slovin's formula [24] based on the total number of nurses and pharmacists residing in the study area was 98 and assumed $5 \%$ of margin error. The minimum sample size required for the study was calculated as 79 . Considering $10 \%$ of the non-response rate, the total sample was increased to be 89 .

\section{Study Instrument}

Based on prior related studies reported in the literature $[13,17,18,21,23,25,26]$, a questionnaire was developed and adapted which was then subjected to a review and validation process by experts from within the research team and outside to ensure that the survey was adequately comprehensive. For the determination of the validity, reliability, and clarity of the questionnaire, a pilot study was carried out. The feedback was analyzed and the questionnaire modified accordingly. The questionnaire included demographics, knowledge, attitude, and practice of HCPs (nurses and pharmacists).

For the pre-KAP study of PV, 12 knowledge-based, 4 attitudes and 10 practice questions were designed, and post-study included 12 knowledge questions and 4 attitude-based questions. Multiple-choice responses to knowledge-based questions were completed by the participants. The HCPs who attended the PV training were approached and the objectives of the study were explained. Written informed consent from the participants was taken and they were assured that their participation in this study is voluntary and confidentiality will be maintained.

\section{Validity and reliability}

The study tool developed was discussed with subjected related experts and suggestions were integrated. The validity of the instrument was maintained by developing the study tool based on objectives of the study, extensive literature review, consulting with a statistician, seeking the opinion of pharmacy, 
pharmacology, and PV, research experts for accuracy and adequacy of the content and peer review at the beginning and throughout the study. The questionnaire was tested for readability and ease of understanding. The reliability of the instrument tool was maintained by pretesting with $10 \%$ of the total sample size. Internal consistency was measured by calculating Cronbach's alpha value, which was 0.76 , indicating good internal consistency. After pretesting, necessary changes were made such as simplified to the level of understanding by participants.

\section{Ethical Approval}

The ethical approval of the current study was approved by the Institutional Review Committee (IRC) of NCHRC (Ref No IRC NCH 002). All HCPS were informed and explained the aims and objectives of the study and invited to participate. Written informed consent was obtained from all participants. Privacy and confidentiality were maintained by not disclosing the name of the participants and ensuring them, that collected information was used only for the study purpose.

\section{Process}

The questionnaire was distributed to 89 HCPs who attended training on PV. All participants were contacted directly in their respective departments after explaining the purpose of the study and invited to participate. The questionnaires were distributed and the participants were given $30 \mathrm{~min}$ to complete and return the same. Any clarification needed in understanding the questionnaires and additional time to complete the questionnaire was provided if required. Those nurses and pharmacists who were busy at that time were requested to return the duly filled questionnaire within one week. After the pre-test, the training was conducted given to all nurses and pharmacists working in the nursing and pharmacy department in NCHRC who had completed the pre-test. The data was collected by one of the authors who is a pharmacist in both pre and post-study.

\section{Educational Intervention (Training in PV and ADRs)}

For an educational intervention, training was given to nurses and pharmacists. At first, a brief introduction was given to the participants regarding the objectives of training on "pharmacovigilance and ADR". The training was given by the team of a focal person of pharmacovigilance, clinical pharmacist and senior hospital pharmacist.

The training was initiated with an overview of ADRs and PV where the definition of PV and ADR, types of ADRs were covered which was followed by the history of PV in Nepal, PV Network of Nepal, Introduction to National and Regional PV Centers of Nepal. The ADR reporting form developed by NCHRC was introduced to the participants and training to fill ADRs reporting form was also discussed. In the training, the role of HCPs in PV was also discussed. Similarly, the demonstration of Vigiflow was given to all the participants. 
The duration of the interactive training was around 2 hours. The teaching-learning aids used during training were PowerPoint presentations, posters, and demonstration of ADR reporting form.

\section{Data Analysis}

The data was systematically checked for errors and analyzed using IBM SPSS for Windows, Version 21.0. Armonk, NY: IBM Corp. After the training, the post-test was conducted; both the pre and post KAP survey questionnaires were analyzed, question-wise and their percentage value was calculated. We also compared and evaluated the knowledge and attitude score of the HCPs. The mean score was calculated for assessing the pre-survey KAP level among nurses and pharmacists. Based on a Likert scale, attitude questions were scored. Minimum 1 and Maximum 5 scores were given to each response and the mean score was calculated for evaluating attitude towards PV. Similarly, the maximum and minimum score for each practice question was scored as 3 and 0 respectively. The knowledge and attitude scores before and after educational intervention were analyzed with Wilcoxon rank-sum test, using SPSS version 21.0. The p-value less than 0.05 was considered statistically significant.

\section{Results}

\section{Socio-demographics of healthcare professionals}

Eight-nine of invited HCPs (nurses and pharmacists) participated. Table 1 shows the demographic characteristics of the participants. $78(87.6 \%)$ were in the age group of 21-30 years. The vast majority of participants were female $76(85.4 \%)$ and $13(14.6 \%)$ were male. The participants working in the department of nursing and pharmacy were 66 (74.2\%) and $23(25.8 \%)$ respectively. Among participants, $55(61.8 \%)$ were staff nurses, 12(13.5\%) were nurses, 15 (16.9\%) were assistant pharmacists, 5 (5.8\%) were pharmacists working at outpatients and inpatients pharmacy of the hospital and only $2(2.2 \%)$ were clinical pharmacists working at clinical wards and taking clinical round. The majority of participants' educational qualifications were of $48(53.9 \%)$ diploma degree (staff nursing and a diploma in pharmacy), 36 (40.4 \%) bachelor degree (Bachelor in nursing and Bachelor in pharmacy) and 5 were graduate degrees (Masters in Nursing and Masters in Clinical Pharmacy).

$<$ Table 1 should be inserted here>

With regard to work experience, the HCPs working in this hospital were well experienced in their profession. $80(89.9 \%)$ of participants had work experiences of $0.2-5.1$ years and 1 (1.1\%) participants had work experience of more than 15 years (Shown in table 2).

$<$ Table 2 should be inserted here>

\section{Knowledge of PV among health care professionals}


Comparison of responses pre and post-training on PV regarding knowledge related questions were shown in Table 3, where there were twelve questions related to the knowledge.

$<$ Table 3 should be inserted here>

\section{Attitude of health care professionals towards PV}

Four questions sought information about the attitude toward ADR reporting. Question no. 13 was about the attitude of reporting of ADRs as the exploration of mistakes of HCPs. Question no. 14 was about the necessity of reporting of adverse drug reaction and Question no. 15 was about whether reporting ADR will increase patient safety. Question no. 16 asked an opinion about establishing an ADR monitoring center in every hospital. Table 4 and 5 show the attitude related responses of HCPs before and after an educational intervention.

$<$ Table 4 should be inserted here $>$

The opinion of the participants about establishing the regional PV center)in every hospital was shown in Table 5. After the educational interventions, the opinion about establishing ADR monitoring center in every hospital was found to be better than before.

$<$ Table 5 should be inserted here $>$

Practice of the PV

The practice of the PV in the hospital by HCPs is shown in table 6.

$<$ Table 6 should be inserted here>

\section{Factors discouraging reporting of ADRs}

The factors that discouraged participants from reporting ADR is shown in Figure 1. Majority of the participants responded to the statement that "Difficult to decide whether ADR has occurred or not", which was followed by the statement "Lack of time to report ADR".

<Figure 1 should be inserted here>

\section{Recommendations for improving ADRs reporting}

The participants provided the recommendations for improving ADRs reporting which was shown in table 7. Twenty-one (23.6\%) of them suggested for frequent PV awareness programs via CME/ workshop.

$<$ Table 7 should be inserted here> 


\section{Assessment of knowledge and attitude scores before and after the educational intervention}

The comparison of knowledge and attitude scores before and after the educational intervention was shown in Table 8.

$<$ Table 8 should be inserted here>

\section{Discussion}

The present questionnaire-based survey was conducted at a regional PV center at an oncology hospital in Nepal with the aim to assess the impact on HCPs (nurses and pharmacists) before and after an educational intervention. Previously no any study was conducted in a regional PV center attached to the cancer hospital [5], regarding PV and ADR reporting, therefore this study was carried out to assess the knowledge and attitude of ADR reporting among HCPs (nurses and pharmacists) in this hospital, also the factors which influence ADR reporting are discussed. When it comes to reporting ADRs, the KAP study is considered as the leading study.

Several studies in Nepal which have reported that HCPs have a lack of knowledge regarding the PV before any kind of educational intervention [15, 17-20]. However, there are only very few limited studies $[21,22]$ that have assessed the PV knowledge after educational intervention among HCPs of tertiary care hospital, and community pharmacists [23]. To the best of our knowledge, the present study is the first to assesses the impact of education on PV at a regional PV center of an oncology based hospital in Nepal.

The current study showed a higher percentage of females (85.4\%) than males as HCPs in the oncology hospital. These findings are similar to the studies conducted at different hospitals in Nepal $[15,17,19,21]$ These findings were also similar to studies conducted at different countries such as neighboring countries India [25], and other countries like Japan [27], Iran [28, 29], UAE [30] and Turkey [10]. While subclassifying participants, most of them were nurses. The reason for being more female and nurses in this study could be explained by the preference of females to choose the nursing career compared to males $[15,20]$. However, there is a recent trend of males joining nursing as a career [31]. Most of the participants were found to be in the age group of 21-30 years and were qualified in their professional work with the mean $\pm S D$ of age was found to be $25.88 \pm 4.131$. The average age of HCPs in our study ranged between $20-46$ years which is similar to studies [15,23, 28-30], unlike study conducted at Turkey [10] where the maximum age group was 50-55 years. With regard to work experience, the HCPs working in this hospital were well experienced in their profession. Eighty (89.9\%) of the participants had work experiences of 0.25.1 years and 1 (1.1\%) participants had work experience of more than 15 years. In similar other studies $[32,33]$, participant's age and work experience have shown an impact of PV activities and ADR reporting as shown in other studies. However, in the other studies [34,35], there was no statistical difference found between ADRs reporting practicing and other independent variables including age, gender, and experience in years. 
Majority of participants educational qualifications were 48 (53.9\%) diploma degree (staff nursing and a diploma in pharmacy) and 36 (40.4\%) bachelor degree (Bachelor in nursing and Bachelor in pharmacy) which is similar to study conducted by Santosh KC et al [15] that was conducted at four regional PV of Nepal. These findings are also similar to the study by John LJ et al [30] at UAE, unlike Hanafi et al. wherein, the majority were undergraduates and graduates [29]. The probable reason may be due to the maximum number of diploma staff in hospitals as these professionals can be paid less than an undergraduate degree and graduate degree.

Majority of the participants responded that it was difficult for them to decide whether ADR has occurred and lack of time as major factors that discourage HCPs from reporting ADRs. Difficulty in deciding ADR and lack of time are reported by other studies conducted in Nepal $[15,17,19]$ and in other countries [30, 36-38] In studies from other countries, reasons for under-reporting of an ADR were found as uncertainty concerning the causal relationship between the ADR, too trivial to report, yellow card unavailability, lack of knowledge about the reporting procedure unavailability of the reporting center mailing address, unavailability of the ADR report form, lack of knowledge of the existence of a national ADR reporting system, and belief that the ADR in question was already well known, ADR is not serious, and the drug, forgetting to report the ADR and ignorance of reporting procedure [27,33,35,39-42].

The majority of the participants suggested "Keep ADR register in all the wards and OPD"," Frequent Pharmacovigilance awareness via Continuing medical education(CME) / workshop "and "Include ADR forms along with case sheet". They also suggested for a frequent pharmacovigilance awareness through the means of CME or workshop, including ADRs forms along with the medical case sheet of the patients, making an institutionalized protocol for reporting ADRs. These suggestions made by participants were almost similar to other studies in different hospitals in the world $[25,30,38]$. These suggestions were almost similar to other studies conducted in other countries which show that educational interventions and other activities help to encourage ADR reporting increase awareness to ADRs and then increase the reporting rates of ADRs [20,21,25,30,38,43-45]. Drug and Therapeutics Committee (DTC) also plays an active leading role in the advancement of medicine safety and strengthening PV centers at the hospital [46]. Practical training or workshop regarding PV might assist to resolve this up-and-coming problem of underreporting of ADRs at the hospital [47]. A systematic simulated environment and workshop on PV should be conducted for the HCPs (pharmacists, nursing staff, and even medical doctors) and intervallic interaction and interprofessional collaborations should be done to know the difficulties they are facing. Clinical pharmacists or pharmacists also play a vital role in PV and increasing ADR reporting [48].

The knowledge score was found to be low before an educational intervention among HCPs which is similar to several studies conducted in Nepal $[15,17,20,21,23]$ and other countries $[10,28,29,47,49]$. However, the knowledge score was found to be increased after the educational intervention. These findings are almost similar to other studies $[21,23,25]$ This evidence clearly showed that after the introduction of educational intervention on PV, knowledge of HCPs were improved. When it comes to ADRs reporting, knowledge regarding $A D R$ is very important which is very important for nurses and pharmacists. They should possess great knowledge of ADR and the process of reporting ADRs to the PV 
center. Among nurses and pharmacists, pharmacists have good knowledge of PV. While, the score was good after -post-study of HCPs working in the hospital which clarifies that PV course, training should be provided to all HCPs in Nepal.

This study revealed that a majority of participants believed that ADR reporting is necessary and increase patient safety. An interesting finding was found in this study, where the attitude score was found to be decreased slightly after the educational intervention. This result was found to be different than other studies $[18,21,23,25]$. However, since most of the nurses and pharmacists consider ADR reporting is necessary, they should overcome the obstacles in reporting ADR and report ADR voluntarily, whenever they encountered and should consider ADR reporting as their professional obligation.

A pre-training study among HCPs of the hospital showed a score of attitude $5.56 \pm 1.616(4-10)$. and posttraining showed $6.97 \pm 1.793(4-12)$. These findings are almost similar to other studies $[21,23,25]$. This evidence clearly showed that after the introduction of educational intervention on PV, attitudes of HCPs were improved.

The present study showed that the change in knowledge and attitude of the participants after PV education yet this study couldn't demonstrate the adjustment in the practices of the participants because of time confinements which are the major limitations of this study. The other limitations of this study contain; the results were of a single-center and fewer sample size. The study can be additionally reached out to other governmental and non-governmental hospitals in Nepal, to sum up, these findings of the study.

\section{Conclusion}

In conclusion, the preliminary findings of this current study presented that the educational intervention improved the PV knowledge and attitude scores of the nurses and pharmacists. It also suggests that training on PV and ADRs tends to have a positive impact on knowledge and attitude nurses and pharmacists of the hospital.

\section{Declarations}

\section{Abbreviations}

ADR: Adverse Drug Reactions

DDA: Department of Drug Administration

HCPs:Healthcare Professionals

KAP:Knowledge, Attitude and Practice

NCHRC: Nepal Cancer Hospital Research Center 
PV: Pharmacovigilance

\section{Ethics approval and consent to participate}

The ethical approval of the current study was approved by the Institutional Review Committee (IRC) of NCHRC (Ref No IRC NCH 002). All HCPs were informed and explained the aims and objectives of the study and invited to participate. Written informed consent was obtained from all participants. Privacy and confidentiality were maintained by not disclosing the name of the participants and ensuring them, that collected information was used only for the study purpose.

\section{Consent for publication}

Written informed consent from study participants was obtained for publication.

\section{Availability of data and materials}

The datasets used and/or analyzed during the current study are available from the corresponding author on reasonable request.

\section{Competing interests}

The authors declare that they have no competing interests

\section{Funding}

This research did not receive any specific grant from funding agencies in the public, commercial or notfor-profit sectors.

\section{Authors' contributions}

SS (a) and BA conceptualized the study, coordinated and supervised the data collection process, carried out the statistical analysis, drafted and critically reviewed the manuscript and prepared the manuscript for submission. SS (b), PK, RB and BS designed the data collection forms and coordinated and supervised data collection. RB and SS (b) coordinated and supervised data collection. BS and SS (a) performed the statistical analysis and revised the manuscript. All authors read and approved the final manuscript.

\section{Acknowledgments}

The authors wish to thank all the study participants for their contribution to this research. The authors would like to acknowledge Dr. Sudip Shrestha, Dr. Subish Palaian, Dr. PR Shankar and Dr. Nisha Jha for their support during the concept and review of the manuscript.

\section{Authors' information (optional)}




\section{References}

1. Organization WH. Safety of medicines: a guide to detecting and reporting adverse drug reactions: why health professionals need to take action. Geneva: World Health Organization, 2002.

2. Wiedenmayer K, Summers RS, Mackie CA, Gous AG, Everard M, Tromp D, et al. Developing pharmacy practice: a focus on patient care: handbook. Geneva: World Health Organization, 2006.

3. Organization WH. WHO guidelines on safety monitoring of herbal medicines in pharmacovigilance systems. 2004.

4. Santosh K, Tragulpiankit P, Gorsanam P, Edwards I, Alam K. Strengthening the Pharmacovigilance Programme in Nepal. Nepal Journal of Epidemiology. 2013;3(1):230-5.

5. Shrestha S, Shrestha S, Khanal S. Establishment of the first cancer hospital-based pharmacovigilance center in Nepal. Research in Social and Administrative Pharmacy. 2018;14(11):1088-9.

6. Binu V, Chandrashekhar T, Subba S, Jacob S, Kakria A, Gangadharan P, et al. Cancer pattern in Western Nepal: a hospital based retrospective study. Asian Pacific Journal of Cancer Prevention. 2007;8(2):183.

7. Pitts PJ, Le Louet H, Moride Y, Conti RM. 21st century pharmacovigilance: efforts, roles, and responsibilities. The Lancet Oncology. 2016;17(11):e486-e92.

8. Sultana J, Cutroneo P, Trifirò G. Clinical and economic burden of adverse drug reactions. Journal of pharmacology \& pharmacotherapeutics. 2013;4(Suppl1):S73.

9. Shrestha S, Shakya R, Shrestha S, Shakya S. Adverse drug reaction due to cancer chemotherapy and its financial burden in different hospitals of Nepal. Int J Pharmacovigil. 2017;2:1-7.

10. Güner MD, Ekmekci PE. Healthcare professionals' pharmacovigilance knowledge and adverse drug reaction reporting behavior and factors determining the reporting rates. Journal of drug assessment. 2019;8(1):13-20.

11. Rivkees SA. Primum non nocere (first, not to harm) and secundus, opinio vulnero (second, report the harm). International journal of pediatric endocrinology. 2009;2009(1):303509.

12. Wysowski DK, Swartz L. Adverse drug event surveillance and drug withdrawals in the United States, 1969-2002: the importance of reporting suspected reactions. Archives of internal medicine. 2005;165(12):1363-9.

13. Alsaleh FM, Alzaid SW, Abahussain EA, Bayoud T, Lemay J. Knowledge, attitude and practices of pharmacovigilance and adverse drug reaction reporting among pharmacists working in secondary and tertiary governmental hospitals in Kuwait. Saudi pharmaceutical journal. 2017;25(6):830-7.

14. Osakwe A, Oreagba I, Adewunmi AJ, Adekoya A, Fajolu I. Impact of training on Nigerian healthcare professionals' knowledge and practice of pharmacovigilance. International Journal of Risk \& Safety in Medicine. 2013;25(4):219-27.

15. Santosh K, Tragulpiankit P, Gorsanan S, Edwards IR. Attitudes among healthcare professionals to the reporting of adverse drug reactions in Nepal. BMC Pharmacology and Toxicology. 2013;14(1):16. 
16. Sharma S, Khanal T, Shrestha S, Adhikari B. A celebration of World Pharmacist Day 2018 focusing to strengthen the pharmacy services at an oncology-based hospital in Nepal: Inspiration for others in developing countries. Research in Social and Administrative Pharmacy. 2019;15(1):117-8.

17. Palaian S, Ibrahim MI, Mishra P. Health professionals' knowledge, attitude and practices towards pharmacovigilance in Nepal. Pharmacy practice. 2011;9(4):228.

18. Subish P, Mohamed Izham M, Mishra P. Evaluation of the knowledge, attitude and practices on adverse drug reactions and pharmacovigilance among healthcare professionals in a Nepalese hospital-a preliminary study. Internet Journal of Pharmacology. 2008;6(1).

19. Gurung RS, Shrestha D, Thapa R. Assessment on knowledge, attitude and practice of pharmacovigilance among the healthcare professionals in a tertiary hospital of Kathmandu. Nepal Medical College Journal. 2019;21(1).

20. Danekhu K, Shrestha S, Aryal S, Shankar PR. Health-care Professionals' Knowledge and Perception of Adverse Drug Reaction Reporting and Pharmacovigilance in a Tertiary Care Teaching Hospital of Nepal. Hospital Pharmacy. 2019:0018578719883796.

21. Jha N, Rathore DS, Shankar PR, Gyawali S, Alshakka M, Bhandary S. An educational intervention's effect on healthcare professionals' attitudes towards pharmacovigilance. The Australasian medical journal. 2014;7(12):478.

22. Jha N, Rathore DS, Shankar PR, Bhandary S, Alshakka M, Gyawali S. Knowledge, Attitude and Practice Regarding Pharmacovigilance and Consumer Pharmacovigilance among Consumers at Lalitpur District, Nepal. Journal of Nepal Health Research Council. 2017;15(1):31-7.

23. Jha N, Rathore DS, Shankar PR, Bhandary S, Pandit RB, Gyawali S, et al. Effect of an educational intervention on knowledge and attitude regarding pharmacovigilance and consumer pharmacovigilance among community pharmacists in Lalitpur district, Nepal. BMC research notes. 2017;10(1):4.

24. Slovin E. Slovin's formula for sampling technique. Retrieved on February. 1960;13:2013.

25. Ganesan S, Sandhiya S, Reddy KC, Subrahmanyam D, Adithan C. The impact of the educational intervention on knowledge, attitude, and practice of pharmacovigilance toward adverse drug reactions reporting among health-care professionals in a tertiary care hospital in South India. Journal of natural science, biology, and medicine. 2017;8(2):203.

26. Meher BR, Joshua N, Asha B, Mukherji D. A questionnaire based study to assess knowledge, attitude and practice of pharmacovigilance among undergraduate medical students in a Tertiary Care Teaching Hospital of South India. Perspectives in clinical research. 2015;6(4):217.

27. Tsuchiya M, Esashi A, Obara T, Inooka K, Mano N, Takamura C. Effect of Educational Interventions on Adverse Drug Reaction Reporting in a Cancer Institute in Japan: A Questionnaire Study. Hospital Pharmacy. 2019;54(2):93-9.

28. Hajebi G, Mortazavi SA, Salamzadeh J, Zian A. A survey of knowledge, attitude and practice of nurses towards pharamacovigilance in Taleqani Hospital. Iranian journal of pharmaceutical research: IJPR. 2010;9(2):199. 
29. Hanafi S, Torkamandi H, Hayatshahi A, Gholami K, Javadi M. Knowledge, attitudes and practice of nurse regarding adverse drug reaction reporting. Iranian journal of nursing and midwifery research. 2012;17(1):21.

30. John LJ, Arifulla M, Cheriathu JJ, Sreedharan J. Reporting of adverse drug reactions: an exploratory study among nurses in a teaching hospital, Ajman, United Arab Emirates. DARU Journal of Pharmaceutical Sciences. 2012;20(1):44.

31. Prakash S, Yadav P, Yadav K. Perspectives of developing nursing education in Nepal. Nurse Care Open Acces J. 2018;5(4):214-20.

32. Khalili H, Mohebbi N, Hendoiee N, Keshtkar A-A, Dashti-Khavidaki S. Improvement of knowledge, attitude and perception of healthcare workers about ADR, a pre-and post-clinical pharmacists' interventional study. BMJ open. 2012;2(1):e000367.

33. Figueiras A, Herdeiro MT, Polónia J, Gestal-Otero JJ. An educational intervention to improve physician reporting of adverse drug reactions: a cluster-randomized controlled trial. Jama. 2006;296(9):1086-93.

34. Ngorsuraches S, Li SC. Thai pharmacists' understanding, attitudes, and perceived barriers related to providing pharmaceutical care. American journal of health-system pharmacy. 2006;63(21):2144-50.

35. Okezie EO, I FO. Adverse drug reactions reporting by physicians in Ibadan, Nigeria.

Pharmacoepidemiology and drug safety. 2008;17(5):517-22.

36. Gupta SK, Nayak RP, Shivaranjani R, Vidyarthi SK. A questionnaire study on the knowledge, attitude, and the practice of pharmacovigilance among the healthcare professionals in a teaching hospital in South India. Perspectives in clinical research. 2015;6(1):45.

37. Li Q, Zhang S-M, Chen H-T, Fang S-p, Yu X, Liu D, et al. Awareness and attitudes of healthcare professionals in Wuhan, China to the reporting of adverse drug reactions. Chinese medical journal. 2004;117(6):856-61.

38. Oshikoya KA, Awobusuyi JO. Perceptions of doctors to adverse drug reaction reporting in a teaching hospital in Lagos, Nigeria. BMC Clinical Pharmacology. 2009;9(1):14.

39. Walker R, Edwards C, Edwards C. Clinical pharmacy and therapeutics: Churchill Livingstone Edinburg; 2003.

40. Grootheest V. Attitudinal survey of voluntary reporting of adverse drug reactions. British journal of clinical pharmacology. 1999;48(4):623-7.

41. Bateman D, Sanders G, Rawlins M. Attitudes to adverse drug reaction reporting in the Northern Region. British journal of clinical pharmacology. 1992;34(5):421.

42. Bäckström M, Mjörndal T, Dahlqvist R, Nordkvist-Olsson T. Attitudes to reporting adverse drug reactions in northern Sweden. European journal of clinical pharmacology. 2000;56(9-10):729-32.

43. Leporini C, Marrazzo G, Mumoli L, Esposito S, Gallelli L, Mangano G, et al. Adverse drug reactions reporting in Calabria (Southern Italy) in the four-year period 2011-2014: impact of a regional pharmacovigilance project in light of the new European Legislation. Expert opinion on drug safety. 2017;16(5):515-22. 
44. Schutte T, van Eekeren R, Richir M, van Staveren J, van Puijenbroek E, Tichelaar J, et al. The adverse drug reaction reporting assignment for specialist oncology nurses: a preliminary evaluation of quality, relevance and educational value in a prospective cohort study. Naunyn-Schmiedeberg's archives of pharmacology. 2018;391(1):17-26.

45. Varallo FR, Planeta CS, Mastroianni PdC. Effectiveness of pharmacovigilance: multifaceted educational intervention related to the knowledge, skills and attitudes of multidisciplinary hospital staff. Clinics. 2017;72(1):51-7.

46. Ghimire BR, Shrestha S, Adhikari B, Shrestha S. Establishment and Achievements of Drug and Therapeutic Committee at the Oncology-Based Hospital of Nepal. Indian Journal of Pharmacy Practice. 2019;12(1):41.

47. Said ASA, Hussain N. Adverse Drug Reaction Reporting Practices Among United Arab Emirates Pharmacists and Prescribers. Hospital Pharmacy. 2017;52(5):361-6.

48. Shrestha S, Shrestha S, Palaian S. Can clinical pharmacists bridge a gap between medical oncologists and patients in resource-limited oncology settings? An experience in Nepal. Journal of Oncology Pharmacy Practice. 2019;25(3):765-8.

49. Shanko H, Abdela J. Knowledge, Attitudes, and Practices of Health Care Professionals Toward Adverse Drug Reaction Reporting in Hiwot Fana Specialized University Hospital, Harar, Eastern Ethiopia: A Cross-sectional Study. Hospital Pharmacy. 2018;53(3):177-87.

\section{Tables}

Due to technical limitations, all tables are only available for download from the Supplementary Files section.

\section{Figures}




\section{Factors discouraging from reporting ADRs}

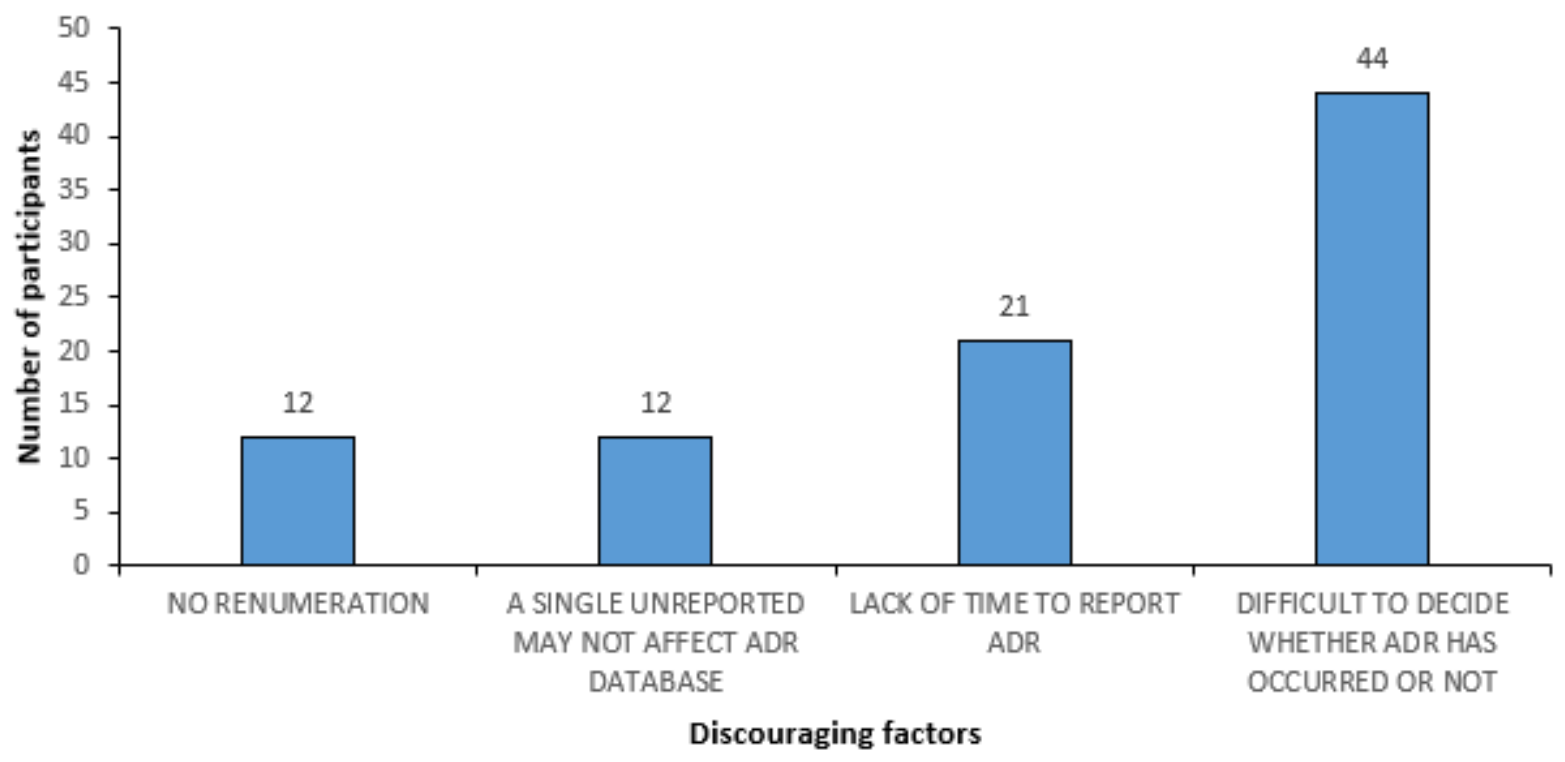

Figure 1

Factors discouraging reporting of ADRs

\section{Supplementary Files}

This is a list of supplementary files associated with this preprint. Click to download.

- Tables.docx 